\title{
Cost-Effectiveness Analysis of Vedolizumab Compared with Other Biologics in Anti-TNF-Naïve Patients with Moderate-to-Severe Ulcerative Colitis in Japan
}

\author{
Luis Hernandez ${ }^{1} \cdot$ Hiroyo Kuwabara ${ }^{2} \cdot$ Anshul Shah $^{1} \cdot$ Kaoru Yamabe $^{2} \cdot$ Heather Burnett $^{3} \cdot$ Kyle Fahrbach $^{1}$. \\ Maria Koufopoulou ${ }^{4} \cdot$ Ryuichi Iwakiri ${ }^{2}$
}

Published online: 24 September 2019

(c) The Author(s) 2019

\begin{abstract}
Background Vedolizumab (VDZ) was approved by the Japanese Ministry of Health, Labor and Welfare in 2018 for the treatment of patients with moderate-to-severe active ulcerative colitis (UC). The comparative cost-effectiveness of VDZ compared with other biologics is unknown in Japan. This information could be useful for decision makers at the time of repricing biologics for the treatment of patients with moderate-to-severe UC.

Objective The aim was to assess the cost-effectiveness of VDZ versus other branded biologics for the treatment of patients with moderate-to-severe UC who were anti-tumor necrosis factor (TNF)-naïve, from the Japanese public healthcare payer perspective.

Methods A hybrid decision tree/Markov model was developed to predict the number of patients who achieved response and remission at the end of the induction phase and sustained it during the maintenance phase, translating this into qualityadjusted life-years (QALYs) and costs. Treatment-related adverse events, discontinuation and surgery, and their impact on QALYs and costs were also modeled. A systematic literature review and network meta-analysis were conducted to estimate the comparative efficacy of each treatment versus placebo. Rates of adverse events, surgery, surgery complications, and utilities were from the literature. Costs (2018 Japanese yen) were obtained from the Japanese National Health Insurance drug price list and medical fee table and local claims databases. Clinical and economic outcomes were projected over a lifetime and discounted at $2 \%$ annually.

Results Over a lifetime, VDZ yielded greater QALYs and cost savings compared with golimumab and was cost-effective compared with adalimumab and infliximab (incremental cost-effectiveness ratios $¥ 4,821,940$ and $¥ 4,687,692$, respectively). Deterministic and probabilistic analyses supported the robustness of the findings in the base-case analysis, indicating that VDZ was either dominant or cost-effective in most scenarios and replications. The main limitations of this analysis include excluding tofacitinib and infliximab biosimilar as comparators, health-state utility estimates were obtained from population studies in the United Kingdom, and the impact of subsequent (i.e., second-line) biologic treatment was not evaluated.

Conclusion Our analysis suggests that VDZ is dominant or cost-effective compared with other branded biologics for the treatment of anti-TNF-naïve patients with moderate-to-severe UC in Japan.
\end{abstract}

\section{Introduction}

Ulcerative colitis (UC) is a chronic inflammatory bowel disease that affects the gastrointestinal tract [1]. Patients with

Electronic supplementary material The online version of this article (https://doi.org/10.1007/s40273-019-00841-1) contains supplementary material, which is available to authorized users.

Luis Hernandez

Luis.Hernandez@evidera.com

Extended author information available on the last page of the article
UC suffer from ulcers that generate pus and mucous, which causes inflammation and sores in the lining of the digestive tract [1]. UC is associated with significant morbidity and mortality [2]; in addition, individuals diagnosed with UC have poorer health-related quality-of-life and greater healthcare resource utilization and work productivity loss, compared with individuals without UC [3]. In Japan, the prevalence and incidence of UC have rapidly increased in recent years $[4,5]$. The most recent data from the Japanese Inflammatory Bowel Disease registry reports a prevalence of 121.9 patients with UC per 100,000 persons in 2013 [6]. Data on the incidence of UC in Japan show a significant 


\section{Key Points for Decision Makers}

Cost-effectiveness analysis was recently included as part of the decision-making processes to adjust prices of approved drugs and devices in Japan. The comparative cost-effectiveness of vedolizumab with other branded biologics is unknown in Japan.

As a first-line biologic for patients with moderate-tosevere active ulcerative colitis (UC), VDZ dominated golimumab and was cost-effective compared with adalimumab and infliximab.

The network meta-analysis (NMA) presented addresses the limitations of previous NMAs for treatments of moderate-to-severe active UC. The proposed economic model approach allows to directly use the evidence reported from randomized clinical trials (RCTs) and the comparative efficacy outcomes that can be obtained via an NMA for the maintenance phase, eliminating the need for individual patient data from RCTs for the comparators of interest and/or assumptions on the comparative efficacy of treatments for transition during the maintenance phase that are not reported in RCTs and that cannot be included in an NMA.

increase from 0.08 to 1.95 per 100,000 persons between 1960 and $1991[7,8]$.

There is no curative medical treatment for UC. The aim of current medical treatment is to induce and maintain remission; monitor, prevent, and manage complications; achieve mucosal healing; and improve quality of life $[9,10]$. The appropriate medical treatment depends on the activity, severity and extent of disease [11]. For patients with moderate-to-severe UC who have not sufficiently responded to conventional therapy (CT; including 5-aminosalicylic acids [5-ASAs], immunomodulators, and steroids), Japanese clinical guidelines for UC recommend biologic tumor necrosis factor alpha antagonists (anti-TNF) infliximab (IFX), adalimumab (ADA), and golimumab (GOL); vedolizumab (VDZ), another biologic, which is a selective antagonist that binds exclusively to the $\alpha 4 \beta 7$ integrin heterodimer and is engineered to target lymphocyte trafficking localized in the gut; and tofacitinib (TOF), a Janus kinase inhibitor [11, 12]. If response or remission is achieved, long-term administration of the same therapy should be used for response and remission maintenance and to reduce the likelihood of colectomy $[11,12]$. For patients who relapse after achieving response or remission, remission induction therapy should be administered; however, the guidelines do not provide specific recommendations for remission induction after a relapse has occurred while on a biologic (i.e., whether CT could be tried again or if another biologic should be used) $[11,12]$. Surgery is recommended only for patients in whom adequate medical treatment is ineffective, as well as for patients suffering from colonic perforation, massive bleeding, toxic megacolon, and high-grade dysplasia, or those with severe disease which does not respond to medical treatments $[11,12]$.

The results of cost-effectiveness analyses are used to determine coverage by the publicly funded healthcare system in countries such as England, Canada, and Australia [13]. In Japan, the price and reimbursement for a new drug are discussed at the Central Social Insurance Medical Council (Chuikyo) and approved by the Ministry of Health, Labor and Welfare (MHLW). After approval, the price is listed as the price for reimbursement. List prices are currently revised every 2 years; starting in 2020, they will be revised every year [13, 14]. In April 2019, the Chuikyo started to use the results of cost-effectiveness analysis to adjust prices of approved drugs and devices in Japan: if the results of the cost-effectiveness analysis show an incremental cost-effectiveness ratio (ICER) below $¥ 5$ million per quality-adjusted life-year (QALY) gained, the price is not adjusted; otherwise a price reduction occurs [13]. With this approach, the Chuikyo seeks to avoid delays in the approval and reimbursement of new drugs and to not limit patient's access to new drugs [13].

IFX, ADA, and GOL were approved by the MHLW in 2010, 2013, and 2017, respectively, and VDZ and TOF in 2018 for the treatment of patients with moderate-to-severe UC who have not sufficiently responded to CT [14]. The efficacy and safety of VDZ for the treatment of patients with moderate-to-severe active UC have been demonstrated in an international study, GEMINI I, and a Japanese phase III VDZ study [15, 16]. Previous studies have assessed the longterm clinical and economic consequences and cost-effectiveness of VDZ compared with other biologics for the treatment of patients with moderate-to-severe UC in the context of the United Kingdom (UK), Spain, and the United States (US) [17-20]. However, this information is still unknown in Japan and can be useful for decision makers at the time of repricing biologics for the treatment of patients with moderate-tosevere UC who have not sufficiently responded to CT. In this study, we assessed the cost-effectiveness of VDZ compared with other branded biologics (ADA, GOL, and IFX) for the treatment of patients with moderate-to-severe active UC who have not sufficiently responded to CT from the Japanese public healthcare payer perspective.

\section{Methods}

\subsection{Model Structure}

An economic model using a hybrid decision tree and Markov approach was developed for this analysis (Fig. 1). 
Treatment for patients with moderate-to-severe active UC with a biologic (i.e., ADA, GOL, IFX, VDZ) begins in the treatment induction phase (decision tree; Fig. 1). At the end of the induction phase, patients can achieve remission or response-only (i.e., response without remission). Patients who achieve remission or response-only and do not discontinue treatment due to treatment-related adverse events (AEs) remain on treatment and enter the maintenance phase (Markov model; Fig. 1) in the corresponding health state. During the maintenance phase, patients transition between the remission and response-only health states, unless they worsen and lose their remission or response-only status. Patients can discontinue treatment during the maintenance phase due to AEs at any time. Patients who discontinue biologic treatment due to AEs (during the induction or maintenance phase) switch to induction CT. Patients who do not achieve remission or response-only at the end of induction or who lose their remission or response-only status during the maintenance phase discontinue biologic treatment and can switch to induction CT or can undergo surgery.

Patients initiating CT induction after biologic discontinuation follow a similar pathway to patients starting on a biologic. However, it is assumed that patients on CT do not discontinue it due to AEs, and that patients who do not achieve response at the end of induction undergo surgery or are assumed to remain in active disease until they may, eventually, undergo surgery.

Patients who undergo surgery are assumed to discontinue treatment and enter the surgery section of the Markov model. These patients can achieve remission after surgery without complications or experience post-surgery complications. Once post-surgery complications are managed, patients transition to the post-surgery remission health state. However, patients in post-surgery remission are always at risk of experiencing complications.

Patients may die at any time (i.e., may transition from any health state to the death health state in any model cycle).

\subsection{Model Parameters and Data Sources}

\subsubsection{Patient Characteristics}

The target population of this analysis was adult patients with moderate-to-severe active UC, defined as patients with a complete Mayo score [21] $\geq 6$, who had not had an adequate response with, had lost response to, or were intolerant to a $\mathrm{CT}$ and, therefore, switched to biologic treatment (i.e., antiTNF-naïve patients). The population was $61.6 \%$ male, with

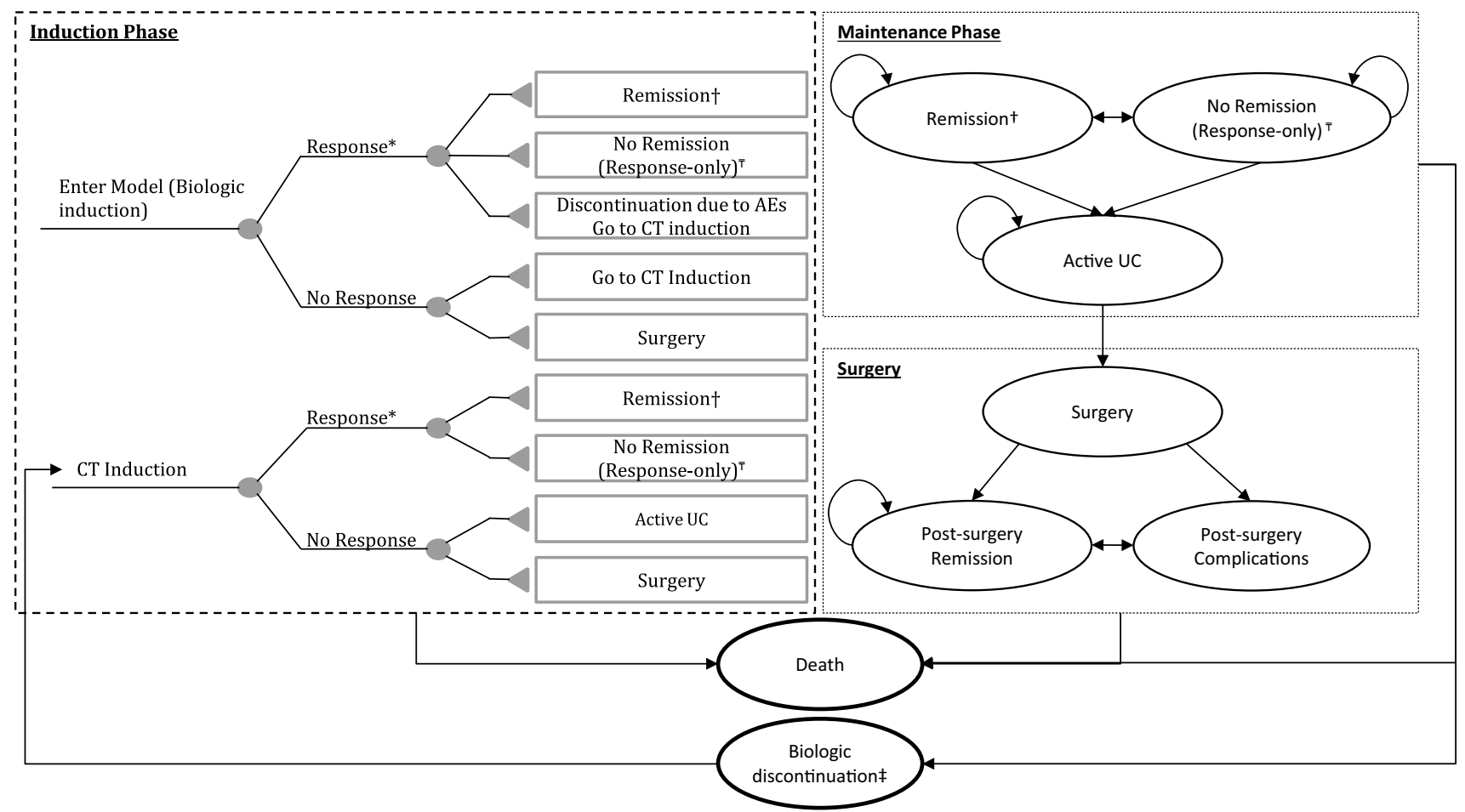

Fig. 1 Model structure. $A E$ adverse event, $C T$ conventional therapy, $U C$ ulcerative colitis. *Reduction in complete Mayo score by $\geq 3$ points and by $\geq 30 \%$ from baseline with an accompanying decrease in the sub-score of rectal bleeding by $\geq 1$ point from baseline or an absolute rectal bleeding sub-score $\leq 1$. Response includes patients who achieve remission and response-only. ${ }^{\dagger}$ Complete Mayo score $\leq 2$ and $\leq 1$ in all sub-scores. ${ }^{\bar{\top}}$ Response without remission. ${ }^{\ddagger}$ Patients treated with a biologic can discontinue treatment at any time due to AEs and switch to CT. Patients treated with a biologic can also switch to induction $\mathrm{CT}$ if they lose their remission or response status during the maintenance phase 
a mean age of 42.8 years (range 16-77), as observed in the Japanese phase III VDZ study [16, 22].

\subsubsection{Treatment Comparators}

For cost-effectiveness analysis in Japan, the comparators should be principally selected among treatments that are expected to be replaced by the comparator of interest (i.e., VDZ in this analysis) at the time when it was introduced to treat the target population [23]. For this reason, the comparators of interest in this analysis included other branded biologics approved for the treatment of moderate-to-severe active UC patients who have not sufficiently responded to CT in Japan: ADA, GOL, and IFX. The following treatments and dosages were considered in analysis:

- VDZ $300 \mathrm{mg}$ at weeks 0,2 , and 6 , and every 8 weeks thereafter

- ADA $160 \mathrm{mg}$ at week $0,80 \mathrm{mg}$ at week 2, and $40 \mathrm{mg}$ every 2 weeks thereafter

- GOL $200 \mathrm{mg}$ at week $0,100 \mathrm{mg}$ at week 2, and $100 \mathrm{mg}$ every 4 weeks thereafter

- IFX $5 \mathrm{mg} / \mathrm{kg}$ weeks 0,2 , and 6 , and every 8 weeks thereafter

CT was not included as a comparator as it is not indicated for patients who have not sufficiently responded to CT (including 5-ASAs, immunomodulators, and steroids), and Japanese guidelines recommend the initiation of biologic treatment for these patients [11, 12]. During the systematic literature review (SLR) (see Appendix A in the electronic supplementary material [ESM], Online Resource 1), only induction studies were found for TOF in anti-TNF-naïve patients with moderate-to-severe UC. Maintenance studies identified for TOF only reported information for a mixed population of both anti-TNF-naïve and anti-TNF-experienced patients, but not for anti-TNF-naïve patients only, which limited the inclusion of TOF as a comparator in the network meta-analysis (NMA) and the model. Surgery was not included as a comparator as it is not recommended in Japanese clinical guidelines for the treatment of patients with moderate-to-severe UC, unless treatment is ineffective $[11,12]$. IFX biosimilar was not included as a comparator as it was not considered among the treatments that are expected to be replaced when VDZ was introduced, because of the very low penetration of IFX biosimila in Japan at the time this analysis started; analyses of the Japanese claims database constructed by JMDC Inc. showed that the percentage of vials of IFX biosimilar prescribed to Japanese patients with UC among the total prescribed vials of IFX branded and biosimilar were $0.8 \%, 1.3 \%, 4.6 \%$, and $7.1 \%$ in 2015, 2016, 2017, and 2018, respectively [24]. However, a scenario using the list price of IFX biosimilar was considered and is discussed in the "Limitations" section.

\subsubsection{Clinical Efficacy}

Clinical efficacy at the end of the induction phase was measured in terms of the percentage of patients who achieve response (including response-only and remission) and remission. The duration of the induction phase was set to 8 weeks as it was the average duration of the time points of efficacy assessment in the induction randomized controlled trials (RCTs) identified during the SLR (Table 4 and Table 5 in Appendix A in the ESM, Online Resource 1).

Clinical efficacy at the end of the maintenance phase was measured in terms of the percentage of patients who remain in remission or response-only (durable response) and in terms of the percentage of patients who remain in or achieve remission at the end of the maintenance phase. The cycle length of the maintenance phase was set to 1 year as the assessment of durable response and remission for the maintenance phase occurred approximately 1 year after the end of the induction phase in the Japanese phase III VDZ study [16].

An SLR was conducted to identify relevant RCTs that assessed the efficacy and safety of ADA, GOL, IFX, TOF and VDZ for the treatment of patients with moderate-tosevere UC who were anti-TNF-naïve. Studies including anti-TNF-treatment experienced patients, or a mix of antiTNF-experienced and anti-TNF-naïve patients were also included if the study reported outcomes separately for the anti-TNF-naïve patients. Thirty-four full-text publications and 11 records identified from gray literature sources and SLR citation lists were eligible for inclusion. These 45 publications collectively reported on 18 trials; 16 trials reported the outcomes of interest for the induction phase (response [including response-only and remission] and remission), and ten for the maintenance phase (durable response and remission). To obtain the relative treatment effects for the biologics of interest versus placebo, Bayesian NMA models were used. All analyses were run in OpenBUGS 3.2.3, using code as referenced in the National Institute for Health and Care Excellence (NICE) Decision Support Unit's series of Technical Support Documents (TSD) on evidence synthesis, TSD2 and TSD5 [25]. The four outcomes of interest were binary. All NMAs involved a 50,000 "run-in" iteration phase and a 50,000-iteration phase for parameter estimation. The posterior mean residual deviance was used to assess the goodness-of-fit of the model, while the deviance information criterion (DIC) was used to assess the comparative fit of fixed and random-effects models.

Unlike newer RCTs (e.g., GEMINI I [15], PURSUIT-M [26], the Japanese phase III VDZ study [16]), which featured re-randomization of responders (including remission 
and response-only) at the end of the induction phase, older trials (e.g., ACT 1 [27], ULTRA 1 [28]) used a treat-through design, in which all patients received the same treatment for 52 weeks during induction and maintenance. Attempts to "convert" re-randomization to treat-through data [29-31], or vice-versa [32], have resulted in a mix of assumptions, calculations, and imputations, not all of which are clearly stated in the papers or examined for risk of bias. We developed a novel method for imputation of treat-through to re-randomization that offers several advantages over prior approaches, avoiding biased estimates against VDZ's comparators and to better mimic current approaches to treatment wherein induction responders remain on therapy. Additional details on the SLR and NMA, including our novel imputation method, are provided in Appendix A in the ESM, Online Resource 1.

The comparative efficacy for each biologic was measured using relative risks (RRs) versus placebo for each efficacy outcome (Table 1). The placebo arm of the Japanese phase III VDZ study was used as the reference to calculate RRs for each biologic versus placebo, based on the results of the NMA, which are presented as odds ratios (ORs) [16]. Appendix B in the ESM, Online Resource 1, shows how the RRs were calculated; the fixed effects models were used for the four outcomes of interest as they showed a lower DIC and residual deviance than the random-effects models and because of the sparsity of the data in the networks.

It was assumed that the treatment effect was constant if patients remained on treatment and that transition probabilities beyond the first year of treatment during the maintenance phase were the same as those estimated for the first year.

For patients initiating CT induction after biologic discontinuation, the placebo arm of the Japanese phase III VDZ study for patients who were anti-TNF-experienced was used: the probability of response (including responseonly and remission) and remission at the end of induction was 0.293 and 0.098 , respectively; the probability of durable response and remission at the end of maintenance was 0.357 and 0.214 , respectively [16].

\subsubsection{Treatment Discontinuation and Adverse Events}

Patients receiving biologic therapy may discontinue treatment due to AEs. The risk of treatment discontinuation due to AEs during the induction and maintenance phase was derived from the RCTs of each biologic [15, 26-28, 33-38]. The incidence rate of treatment discontinuation due to AEs was calculated as the proportion of patients who discontinued treatment due to AEs over the study duration, scaling the study duration to 8 weeks for the induction phase and to 1 year for the maintenance phase. If more than one RCT was used for a specific treatment, a weighted average of the incidence rate of treatment discontinuation due to AEs, the study duration, and the number of patients in each study was calculated. It was assumed that the rate of treatment discontinuation was constant over time, and that beyond the first year of treatment during the maintenance phase, it was the same as for the first year. The rates of treatment discontinuation due to AEs were transformed into probabilities [39] and are shown in Table 1.

Japanese clinical practice guidelines recommend that if response or remission is achieved, long-term administration of the same therapy should be used for response and remission maintenance and to reduce the likelihood of colectomy $[11,12]$. Therefore, no maximum treatment duration was considered for biologics in the model, and patients received treatment for as long as they benefited from it. It was assumed that patients on $\mathrm{CT}$ after discontinuing biologic treatment did not discontinue CT due to AEs.

AEs included in the model were erythema, infusionassociated reaction, injection site reaction, rash, and skin and subcutaneous disorder (Table 1). These AEs were the most commonly reported ( $\geq 10 \%$ incidence) in any arm of the RCTs of each biologic [15, 22, 26, 27, 33-37, 40]. It was assumed that the incidence of AEs was constant over time and that beyond the first year of treatment during the maintenance phase it was the same as for the first year.

\subsubsection{Surgery}

The annual rate of surgery was calculated as $1.10 \%$ during the maintenance phase based on publicly available information: the estimated number of people with UC in Japan $(n=166,060)$ [41]; the percentage of patients with moderate-to-severe UC in Japan (30\%) [42]; and the number of annual UC-related surgeries $(n=305)$ conducted in Japan in the same year in 16 hospitals, out of $390 \mathrm{UC}$ related hospitalizations [43], scaled to the total number of hospitalizations for UC-related surgeries $(n=702)$ : $1.1 \%=[702 \times(305 / 390)] /(166,060 \times 30 \%)$. This estimate was consistent with the estimation of $1 \%$ from a Japanese clinician (Dr. Ryuichi Iwakiri [RI]).

The annual risk of developing surgical complications was based on an analysis conducted by Arai and colleagues (2005), who reported the incidence complications within the first year of surgery to be $46.3 \%$ [44].

\subsubsection{Mortality}

There is no evidence that patients with UC have a lower life expectancy than the general population [45]. Therefore, and consistent with previous cost-effectiveness analyses of biologics in UC [17-19, 46, 47], the risk of death for patients with UC was the same as the all-cause risk of death of the Japanese general population, derived from age- and sexspecific 2016 life tables published by the MHLW in Japan [48], and did not vary between health states in the model. 
Table 1 Treatment efficacy, safety, and discontinuation

\begin{tabular}{|c|c|c|c|c|c|c|}
\hline & VDZ & ADA & GOL & IFX & \multicolumn{2}{|c|}{ Probability $(95 \%$ CI $)[16,22]$} \\
\hline Clinical efficacy & \multicolumn{3}{|c|}{ RR vs. placebo (95\% CI) } & & \multicolumn{2}{|l|}{ Reference (placebo) } \\
\hline \multicolumn{7}{|c|}{ At the end of induction phase } \\
\hline Response & $1.658(1.337-1.957)$ & $1.421(1.220-1.619)$ & $1.587(1.337-1.824)$ & $1.848(1.663-2.019)$ & \multicolumn{2}{|l|}{$0.366(0.221-0.530)$} \\
\hline Remission & $2.451(1.523-3.716)$ & $1.619(1.153-2.209)$ & $2.435(1.613-3.490)$ & $2.833(2.230-3.497)$ & \multicolumn{2}{|l|}{$0.146(0.055-0.291)$} \\
\hline \multicolumn{7}{|c|}{ Maintenance phase, annual probability } \\
\hline Durable response & $2.039(1.672-2.329)$ & $1.359(0.934-1.806)$ & $1.636(1.340-1.916)$ & $1.860(1.399-2.244)$ & \multicolumn{2}{|l|}{$0.357(0.186-0.559)$} \\
\hline Remission & $1.783(1.370-2.144)$ & $1.552(1.066-2.024)$ & $1.404(1.054-1.759)$ & $1.800(1.333-2.198)$ & \multicolumn{2}{|l|}{$0.357(0.186-0.559)$} \\
\hline \multicolumn{7}{|c|}{ Discontinuation due to AEs $[15,26-28,33-38]$} \\
\hline $\begin{array}{l}\text { Induction phase, } \\
\text { 8-week prob- } \\
\text { ability }\end{array}$ & $5.23 \%$ & $5.75 \%$ & $0.40 \%$ & $2.69 \%$ & & \\
\hline $\begin{array}{l}\text { Maintenance } \\
\text { phase, annual } \\
\text { probability }\end{array}$ & $4.17 \%$ & $8.95 \%$ & $8.77 \%$ & $6.31 \%$ & & \\
\hline \multicolumn{4}{|c|}{ Incidence of AEs [15, 22, 26, 27, 33-37, 40] } & & Disutility* [51] & $\begin{array}{c}\text { Cost per } \\
\text { event, } \\
¥[52]\end{array}$ \\
\hline \multicolumn{7}{|c|}{ Induction phase, weekly rate } \\
\hline Erythema & $0.12 \%$ & $0.00 \%$ & $0.00 \%$ & $0.00 \%$ & -0.1100 & 1607 \\
\hline $\begin{array}{l}\text { Infusion-associated } \\
\text { reaction }\end{array}$ & $0.00 \%$ & $0.00 \%$ & $0.00 \%$ & $0.80 \%$ & -0.0300 & 149 \\
\hline $\begin{array}{l}\text { Injection site reac- } \\
\text { tion }\end{array}$ & $0.06 \%$ & $1.16 \%$ & $0.00 \%$ & $0.00 \%$ & -0.0300 & 1607 \\
\hline Rash & $0.09 \%$ & $0.00 \%$ & $0.00 \%$ & $0.00 \%$ & -0.1100 & 1607 \\
\hline $\begin{array}{l}\text { Skin and subcuta- } \\
\text { neous disorders }\end{array}$ & $0.84 \%$ & $0.00 \%$ & $0.00 \%$ & $0.00 \%$ & -0.1100 & 1607 \\
\hline \multicolumn{7}{|c|}{ Maintenance phase, annual rate } \\
\hline Erythema & $2.14 \%$ & $0.00 \%$ & $16.36 \%$ & $0.00 \%$ & -0.1100 & 1607 \\
\hline $\begin{array}{l}\text { Infusion-associated } \\
\text { reaction }\end{array}$ & $0.00 \%$ & $0.00 \%$ & $0.00 \%$ & $17.35 \%$ & -0.0300 & 149 \\
\hline $\begin{array}{l}\text { Injection site reac- } \\
\text { tion }\end{array}$ & $2.14 \%$ & $12.85 \%$ & $9.35 \%$ & $0.00 \%$ & -0.0300 & 1607 \\
\hline Rash & $0.54 \%$ & $0.00 \%$ & $4.48 \%$ & $7.36 \%$ & -0.1100 & 1607 \\
\hline $\begin{array}{l}\text { Skin and subcuta- } \\
\text { neous disorders }\end{array}$ & $12.93 \%$ & $0.00 \%$ & $0.00 \%$ & $0.00 \%$ & -0.1100 & 1607 \\
\hline
\end{tabular}

$A D A$ adalimumab, $A E$ adverse event, $C I$ confidence interval, $G O L$ golimumab, $I F X$ infliximab, $R R$ relative risk, $V D Z$ vedolizumab

*Duration of AEs was assumed to be 8 weeks for all AEs during induction and maintenance

It was assumed that no fatalities occurred due to surgery or post-surgery complications.

\subsubsection{Utilities}

Health state utilities were not available from patients with UC in Japan at the time of this analysis and were obtained from previous studies in patients from the UK (Table 2) [49, 50]. Utility decrements associated with AEs were obtained from a previous cost-effectiveness analysis of VDZ for the treatment of patients with moderate-to-severe UC in the UK (Table 1), assuming the duration of all AEs was 8 weeks during induction and maintenance $[18,51]$.

\subsubsection{Costs}

Direct costs included treatment-related costs (i.e., drug acquisition, administration, and concomitant medications), cost of surgery and surgical complications, disease management costs by health state, and AE management costs. All costs were obtained in 2018 Japanese yen ( $¥)$ and are shown in Table 2.

The cost of biologics and concomitant medications were obtained from Japan's National Health Insurance (NHI) drug list for 2018 [52]. Sharing of vials to minimize vial wastage was not considered for biologics. The list of concomitant medications was health-state specific, based on the 
Table 2 Costs and health-state utilities

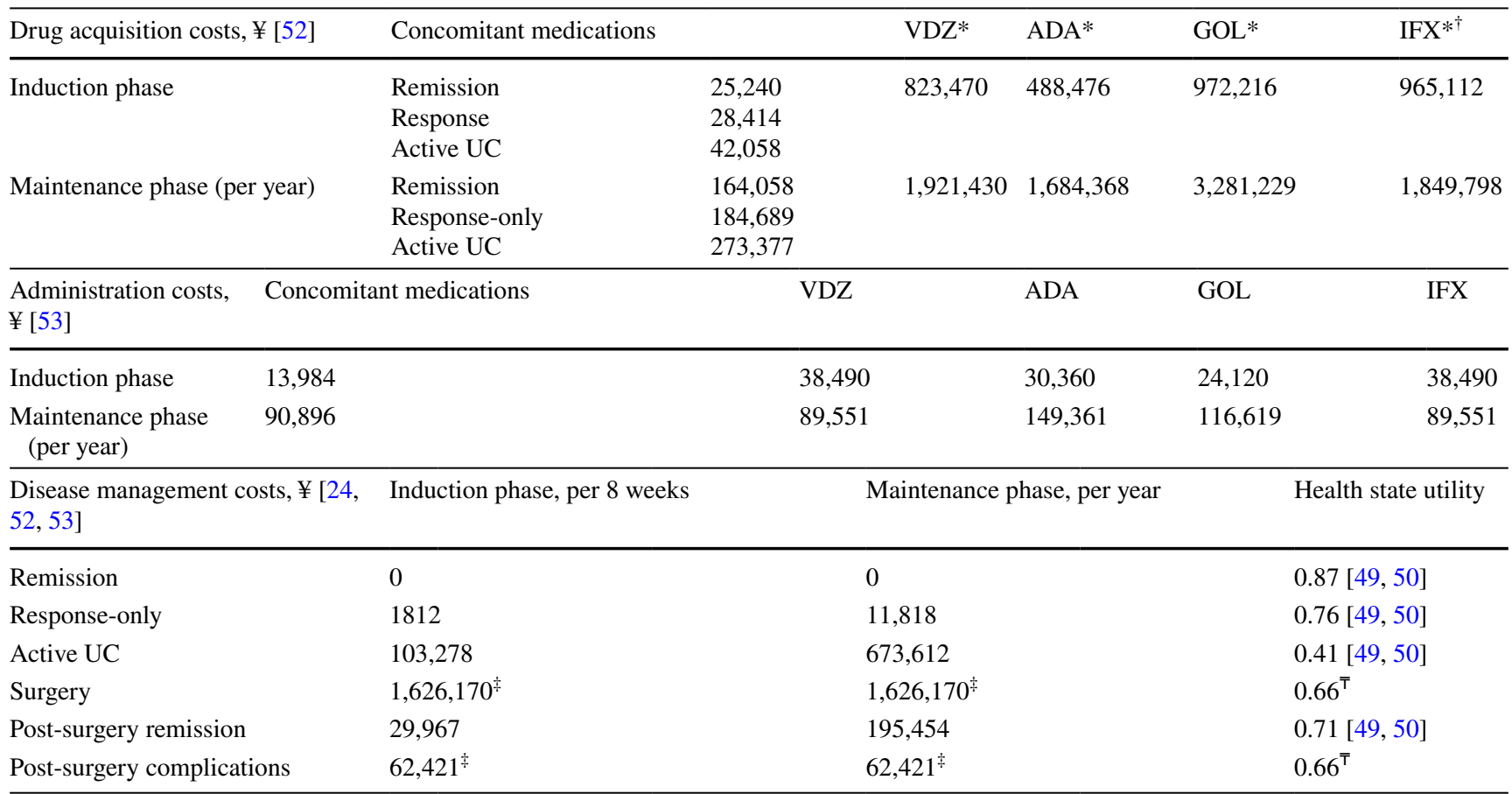

$A D A$ adalimumab, GOL golimumab, IFX infliximab, NICE National Institute for Health and Care Excellence, $U C$ ulcerative colitis, $V D Z$ vedolizumab

*Cost per pack: VDZ $¥ 274,490$ for 1 vial of $300 \mathrm{mg} / 2 \mathrm{~mL}$; ADA $¥ 62,384$ for 1 syringe of $40 \mathrm{mg} / 0.8 \mathrm{~mL}$ and $¥ 121,236$ for 1 syringe of $80 \mathrm{mg} / 0.8 \mathrm{~mL}$; GOL $¥ 121,527$ for 1 syringe of $50 \mathrm{mg} / 4 \mathrm{~mL}$; IFX $¥ 80,426$ for 1 vial of $100 \mathrm{mg} / 20 \mathrm{~mL}$

${ }^{\dagger}$ Calculated using an average number of 3.4 vials per administration, obtained from claims data analyses

Cost of surgery and post-surgery complications were applied as a one-time cost

${ }^{\bar{T}}$ Calculated as the weighted average of the utility score for surgery used in the cost-effectiveness analysis of IFX, ADA, and GOL by the NICE Assessment Group (0.42) during 8 weeks [49] and the utility score for post-surgery remission (0.71) from Woehl and colleagues (2008) [50] for the reminder of the year (i.e., 42 weeks): $0.66=0.42 \times(8 / 52)+0.71 \times(42 / 52)$

concomitant medications reported in the Japanese phase III VDZ study [22]. The frequency of resource use associated with treatment administration and health-state-specific UC management costs were estimated based on analyses of the JMDC database [24], along with consultation with a Japanese clinician (Dr. RI, Appendix C in the ESM, Online Resource 1; Dr. RI was asked to look at the resource use estimates and to validate if they were consistent with his expectations, based on his experience in UC). Unit costs were derived from Japan's NHI medical fee table 2018 [53].

The cost of surgery was based on the mean expenditure per hospitalization observed for the total colectomy anal anastomosis procedure in patients with UC in the JMDC database. The costs of post-surgery complications included a 28-day medical management cost of pouchitis (Appendix C in the ESM, Online Resource 1). The costs of a surgical procedure and complications were accrued as a one-time cost.

For the costs for AE management, only minimal treatment such as the administration of saline solution and antibiotics were considered. The cost of saline solution and antibiotics was obtained from the NHI drug list 2018 [52].

\subsubsection{Model Verification and Validation}

The face validity of the model was established by presenting the model concept and structure, comparators, and assumptions to two health economics experts (Senior Research Scientists within Evidence Synthesis, Modeling and Communication at Evidera, a company which provides consulting and other research services to pharmaceutical, medical device, and other organizations, who were external to the team of authors of this study and who became familiar with the disease area) and one Japanese clinician (Dr. RI), to ensure that the model was designed correctly and rigorously from the modeling standpoint and the perspective of clinical face validity. Extreme-value sensitivity analyses were conducted to determine the technical accuracy of the model and for logical consistency. Upon completion of the model, 
a comprehensive and rigorous quality check was performed validating its logical structure, mathematical formulas and sequences of calculations, as well as the model inputs. Predictive validity was checked by comparing key outcomes, including the number of patients who achieved response and remission at the end of the induction phase and who achieved durable response and remission at the end of the first year of maintenance, to the source data.

\subsubsection{Analyses}

The life-table method for half-cycle correction was used to calculate all model outcomes [54]. As recommended by the guidelines for economic evaluation of drugs and medical devices in Japan, this analysis took the public healthcare payer's perspective, the time horizon of analysis was lifetime, and the annual discount rate for costs and health benefits was $2 \%$ [23]. A treatment was considered cost-effective at ICERs below a conservative willingness-to-pay (WTP) threshold of $¥ 5,000,000$ per QALY gained $[13,55]$.

Deterministic sensitivity analyses (DSAs) were conducted to assess the impact of all model parameters in the ICERs. When possible, 95\% confidence intervals (CIs) were used to vary the parameters. Otherwise, parameters were varied by $\pm 20 \%$.

To account for statistical uncertainties in the model parameters, probabilistic sensitivity analyses (PSAs) were conducted by varying simultaneously the model parameters using the probability distributions and parameters presented in Appendix D in the ESM, Online Resource 1. Drug acquisition and administration costs were not included in the PSA as they were not subject to parameter uncertainty. The model was carried out running 5000 simulations by randomly drawing values of input parameters from their respective distributions and calculating the ICERs for each model run.

\section{Results}

\subsection{Base-Case Analysis}

As shown in Table 3, over a lifetime, treatment with VDZ was associated with more time spent on biologic treatment, response and remission, and fewer surgeries compared with the other biologics. Compared with GOL, VDZ yielded greater QALYs at a lower total cost and was dominant. Compared with ADA and IFX, VDZ yielded greater QALYs at a higher cost, with ICERs below the WTP threshold of $¥ 5,000,000$. Therefore, VDZ was cost-effective compared with ADA and IFX.

Table 3 Base-case outcomes over lifetime

\begin{tabular}{|c|c|c|c|c|}
\hline Outcome (discounted per patients, unless otherwise specified) & VDZ & ADA & GOL & IFX \\
\hline \multicolumn{5}{|l|}{ Clinical outcomes } \\
\hline Life-years & 28.74 & 28.74 & 28.74 & 28.74 \\
\hline Years on biologic treatment & 3.31 & 2.40 & 2.73 & 3.19 \\
\hline Years in response (response-only and remission)* & 2.20 & 1.27 & 1.61 & 2.07 \\
\hline Years in remission* & 1.58 & 0.77 & 1.06 & 1.55 \\
\hline Number of surgeries, per 1000 patients & 2.65 & 2.78 & 2.73 & 2.67 \\
\hline AE disutility & -0.065 & -0.068 & -0.072 & -0.071 \\
\hline Total QALYs & 13.4336 & 13.0594 & 13.1919 & 13.3895 \\
\hline \multicolumn{5}{|l|}{ Cost outcomes, $¥$} \\
\hline Biologic therapy & $6,366,986$ & $3,857,998$ & $8,317,233$ & $6,070,063$ \\
\hline Disease management costs & $22,763,278$ & $23,345,591$ & $23,129,366$ & $22,829,847$ \\
\hline Surgery & $2,308,508$ & $2,381,428$ & $2,357,123$ & $2,323,199$ \\
\hline Post-surgery complications & 512,078 & 536,485 & 528,160 & 516,706 \\
\hline Post-surgery remission & 517,822 & 542,709 & 534,217 & 522,536 \\
\hline $\mathrm{AE}$ costs & 8786 & 8654 & 9075 & 8280 \\
\hline Total cost & $32,477,458$ & $30,672,865$ & $34,875,173$ & $32,270,632$ \\
\hline ICER (VDZ vs. comparator), ¥ per QALY gained ${ }^{\dagger}$ & & $4,821,940$ & Dominant & $4,687,692$ \\
\hline
\end{tabular}

$A E$ adverse event, $A D A$ adalimumab, $G O L$ golimumab, ICER incremental cost-effectiveness ratio, $I F X$ infliximab, $Q A L Y$ quality-adjusted lifeyear, $V D Z$ vedolizumab

*While on biologic treatment

${ }^{\dagger}$ ICERs presented might not exactly match manual calculations done using the total QALYs and total cost, due to rounding 


\subsection{Deterministic Sensitivity Analyses}

The DSA showed that VDZ was dominant or cost-effective versus GOL in all scenarios. Figures 2 and 3 present the results from the sensitivity analyses versus ADA and IFX, respectively, for the top 10 parameters that had the largest effect on the ICERs, in the order of their respective influence. It should be noted that, unlike in other countries, the list price of a drug in Japan is the price for reimbursement covered by the NHI, and this price is revised every 2 years $[13,56]$. Therefore, variations in the cost per pack of VDZ, ADA, GOL, and IFX provide information about the potential ICERs if the list price of any of these biologics were to be revised in the future.

Detailed results of the scenarios for VDZ versus ADA and IFX in which the ICER was above $¥ 5,000,000$ per QALY gained are presented in Appendix E in the ESM, Online Resource 1.

\subsection{Probabilistic Sensitivity Analysis}

Assuming a WTP threshold of $¥ 5,000,000$ per QALY gained, the probability that VDZ produced the greatest expected net benefit was the highest compared to ADA, GOL, and IFX. VDZ was the optimal treatment choice at any WTP threshold $>¥ 4,500,000$ per QALY gained (Fig. 4).

\section{Discussion}

To our knowledge, this is the first study to assess the costeffectiveness of biologics for the treatment of anti-TNFnaïve patients with moderate-to-severe active UC from Japan's public healthcare payer perspective. Findings from this cost-effectiveness analysis can further inform patients and prescribers when considering VDZ over other biologics (ADA, GOL, and IFX), and can be useful for decision makers at the time of repricing biologics. This analysis suggests that long-term treatment with VDZ is associated with clinical benefits over other biologics, including additional time spent in response and remission, fewer surgeries, and more QALYs gained. These benefits were obtained at a lower total cost compared with GOL. VDZ resulted in higher total costs compared with ADA and IFX; however, the resulting ICERs fell below the WTP threshold of $¥ 5,000,000$ per QALY gained, making VDZ cost-effective compared with ADA and IFX. Both DSA and PSA consistently supported the robustness of the findings in the base-case analysis, indicating that VDZ was either dominant or cost-effective in most scenarios and replications.

Our findings are consistent with two recent cost-effectiveness analyses in the UK and Spain that examined VDZ compared with ADA, GOL, and IFX for the treatment of patients with moderate-to-severe UC who were anti-TNF-naïve [18, 19]. Both studies also showed that long-term treatment with VDZ was associated with greater QALYs compared with

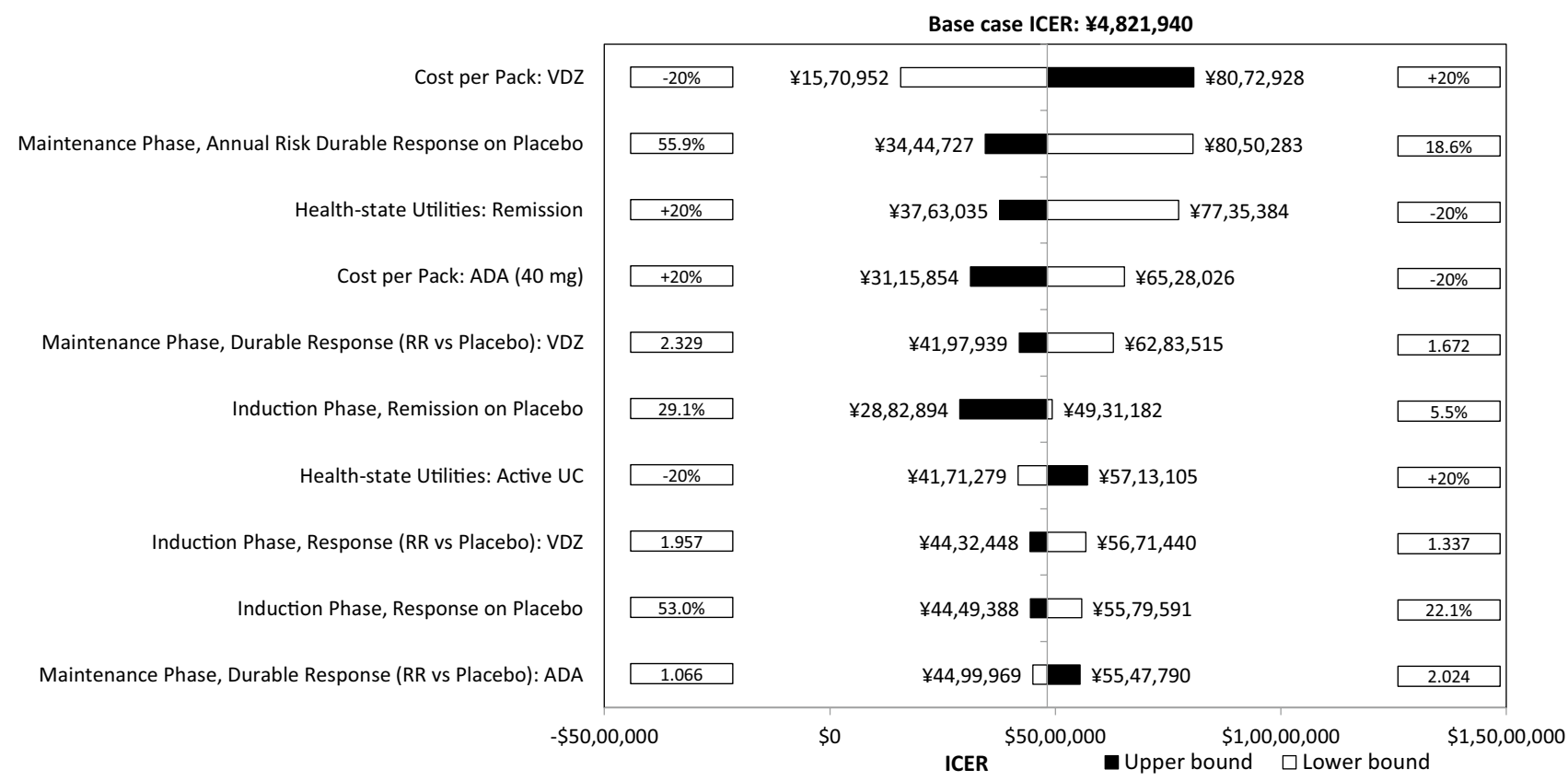

Fig. 2 Deterministic sensitivity analysis VDZ vs. ADA. $A D A$ adalimumab, ICER incremental cost-effectiveness ratio, $R R$ relative risk, $U C$ ulcerative colitis, $V D Z$ vedolizumab 


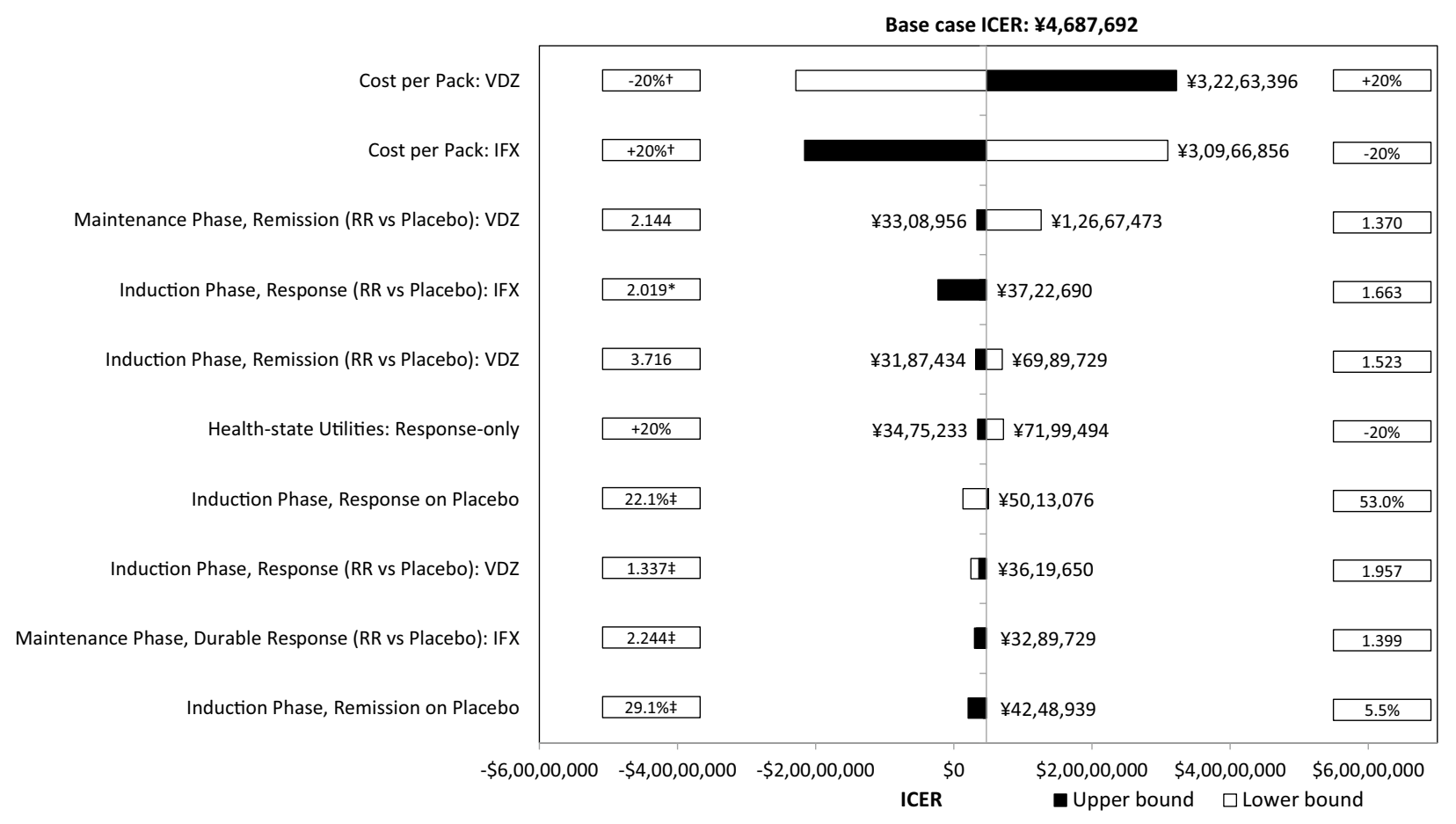

Fig. 3 Deterministic sensitivity analysis VDZ vs. IFX. ICER incremental cost-effectiveness ratio, IFX infliximab, $R R$ relative risk, $V D Z$ vedolizumab. *In this scenario, IFX was dominant (i.e., IFX shown. ${ }^{\dagger}$ In these scenarios, VDZ was dominant (i.e., VDZ was less costly and more effective compared to IFX); ICER not shown. ${ }^{\ddagger}$ In was more effective and less costly compared with VDZ); ICER not these scenarios, VDZ was less costly and less effective compared to IFX; ICER not shown

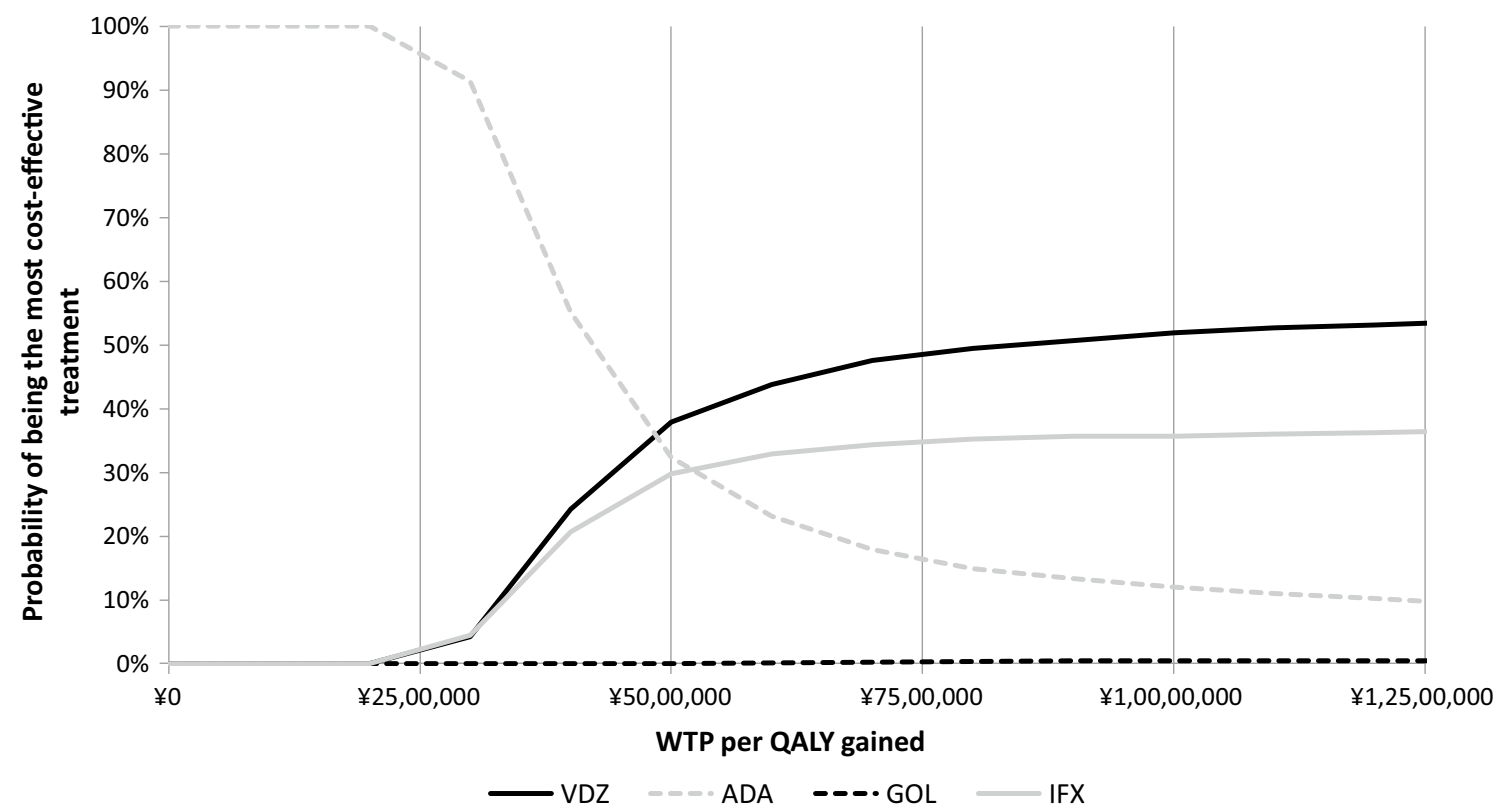

Fig. 4 Multi-way cost-effectiveness acceptability curves. $A D A$ adalimumab, $G O L$ golimumab, $I F X$ infliximab, $Q A L Y$ quality-adjusted life-year, $V D Z$ vedolizumab; WTP willingness-to-pay

ADA, GOL, and IFX $[18,19]$. In the UK analysis, the time horizon was 30 years as a proxy for lifetime, and VDZ was dominant over GOL and IFX and cost-effective compared with ADA [18]. The analysis from Spain used a time horizon of 10 years [19]. This short time horizon made it difficult to directly compare with our cost-effectiveness results [19]. However, when we set the time horizon to 10 years, VDZ remained dominant compared with GOL and cost-effective 
compared with ADA and IFX, with ICERs lower than with a lifetime horizon in the base case ( $¥ 4,089,246$ and $¥ 3,577,489$, respectively). A third study assessed the costeffectiveness of treatment strategies/sequences of treatments for the treatment of moderate-to-severe UC patients who were anti-TNF-naïve in the UK and China [47]. Consistent with our study and the previous studies in the UK and Spain, long-term treatment with VDZ was associated with greater QALYs compared with ADA, GOL, and IFX when all biologics were followed by CT after biologic discontinuation. In our study, the total QALYs for the biologics ranged between 13.07 and 13.43. The study conducted for Spain reported lower QALYs for the biologics, between 5.07 and 6.00, as the time horizon of analysis was 10 years [19]. In the study by Wilson et al. (2018) for the UK, the time horizon of analysis was lifetime and the QALYs for the biologics ranged between 13.79 and 14.08; in this study by Wilson et al., the health states were not based on response and remission, but on disease severity (moderate-severe, mild, and remission) [18]. The utility value used for patients in remission was 0.87 , in line with our analysis and the other studies for the UK, Spain and China [19, 46, 47]; however, the utility values used by Wilson et al., for the mild and moderate-severe UC health states were 0.80 and 0.68 , respectively, which are higher than those for the response-only (0.76) and active UC ( 0.41 or 0.42$)$ health states used in our analysis and the other studies [19, 46, 47]. Although Wilson et al. used lower utility values compared to our analysis for the surgery, post-surgery remission, and post-surgery complications health states ( 0.42 vs. $0.66,0.60$ vs. 0.71 , and 0.42 vs. 0.66 , respectively) [18], the low number of surgeries and complications does not offset the additional QALYs accrued with a higher utility value for the mild and moderate-severe UC health states in the study by Wilson et al. versus those used in our analysis for the response-only and active UC health states. In the study by Wu et al. (2018), the time horizon of analysis was lifetime and the QALYs for biologics (ADA, GOL, IFX, and VDZ) followed by CT after discontinuation ranged between 10.71 and 11.48 in the analysis for the UK, and between 8.16 and 8.92 in the analysis for China [47]. All the efficacy and utility parameters used in the analyses by Wu et al. were the same for the UK and China, except for the life expectancy tables, which were country specific; the difference in the life expectancy seems to be the only explanation for having different QALYs between the analyses for the UK and China, although life-years are not reported in the study to confirm this. In our study, we used Japanese life tables published by the MHLW to model mortality, which could explain the higher QALYs for biologics reported in our study as the life expectancy in Japan (84 years) is higher than that in the UK (81 years) and China (76 years) [57]. The utility values used in our analysis were almost the same as those used by $\mathrm{Wu}$ et al. [47], except for the surgery health states remission ( 0.88 in the study by Wu et al. vs. 0.87 in our analysis), response-only ( 0.76 in both analyses), active UC (0.42 vs. 0.41$)$, post-surgery remission $(0.60$ vs. 0.71$)$, and post-surgery complications $(0.42$ vs. 0.66$)$. We ran a scenario in our model using the utility values used by $\mathrm{Wu}$ et al., and VDZ remained dominant compared with GOL and cost-effective compared with ADA and IFX, with ICERs lower than in the base case ( $¥ 4,358,589$ and $¥ 4,065,464$, respectively).

Our model attempts to overcome limitations associated with previous cost-effectiveness analyses of biologics in the treatment of moderate-to-severe UC. First, NMAs are a common and accepted approach to assess the relative efficacy of multiple treatments in the absence of head-tohead RCTs [58, 59]. For this analysis, we conducted an SLR and NMA, including evidence from a phase III study in Japanese patients with moderate-to-severe UC who are anti-TNF-naïve [16, 22]. Due to differences in RCT designs (e.g., treat-through versus re-randomization), imputation of treat-through studies was required to allow for indirect comparisons of ADA and IFX for the maintenance phase. We developed a novel method for imputation of treat-through design to re-randomization that offers several advantages over prior approaches to avoid biased estimates against VDZ's comparators and to better mimic current approaches to treatment wherein induction responders remain on therapy. To assess the impact of our approach on the costeffectiveness results, we ran a scenario using the results of a previous NMA by Vickers et al. (2016), in which ORs for VDZ, ADA, GOL, and IFX versus placebo were reported for the four outcomes of interest in patients with moderate-tosevere UC who are anti-TNF-naïve [32]. As in our base-case analysis, we transformed the ORs reported by Vickers et al. into RRs using the placebo arm of the Japanese phase III VDZ study as the reference. In this scenario, VDZ remained dominant compared with GOL and cost-effective compared with ADA and IFX, with ICERs lower than in our base case ( $¥ 4,483,564$ and $¥ 3,058,130$, respectively). The ICERs are lower in the scenario using the ORs reported by Vickers et al., because all the clinical outcomes (time on biologic treatment, time in response and remission, and consequently QALYs) improved for VDZ, while they worsened for all the other comparators. It is important to note when comparing our findings with those of the NMA by Vickers et al. that differences in the assumptions and imputation approaches are not the only factors driving differences in the observed results of the NMA and, therefore, the scenarios ran for the cost-effectiveness analysis; our NMA included nine and five additional RCTs reporting the outcomes of interest for induction and maintenance, respectively, including the Japanese phase III VDZ study. However, the approach used by Vickers et al. to impute treat-through data and allow for comparison to re-randomization data includes a strong 
bias in favor of placebo, as they assumed that the number of placebo responders during induction would be the same as the number of treatment responders during induction; this inflated the estimate of durable response and remission during maintenance for placebo and resulted in under-estimation of the efficacy of ADA and IFX compared to placebo, which contributes to the lower ICERs in the cost-effectiveness analyses for VDZ versus ADA and IFX.

Second, previous cost-effectiveness analyses have characterized disease severity during the maintenance phase using three health states, defined by patients' Mayo score: remission (Mayo score 0-2), mild UC (Mayo score 3-5), and moderate-to-severe UC (Mayo score 6-12) [17, 18, 60]. This approach has been criticized by an independent Evidence Review Group (ERG) during a NICE single technology appraisal of VDZ for the treatment of patients with moderate-to-severe UC in the UK, as this approach ignored that patients in the mild and moderate-to-severe UC health states can include both patients with and without response [61]. The ERG suggested that this issue could have been addressed by modeling the maintenance phase transitions between moderate-to-severe UC, response, and remission health states, using the patient-level data from the GEMINI I clinical trial $[15,61]$. We followed the ERG's recommendation, and the model structure is in line with previous models [62]. However, unlike in previous studies, we did not have access to the individual patient data from any RCT of the comparators included in this analysis to derive transition probabilities between the maintenance phase health states. Only with access to patient-level data is it possible to estimate all the transitions between the maintenance phase health states: remission to remission, remission to responseonly, remission to active $\mathrm{UC}$, response-only to responseonly, response-only to remission, response-only to active UC, active UC to active UC. For example, in the study by Tappenden et al. (2016), data relating to response and remission for the comparators included in their analysis were obtained directly from the manufacturer of the biologics, which allowed them to derive all the transition probabilities between the maintenance phase health states for all the comparators [46]. However, most studies will typically have access to the individual patient data from RCTs of one, or at most two, comparators of interest for which all the transition probabilities between the maintenance phase health states can be derived, but meta-analyses and indirect comparisons (e.g., NMA) of relevant RCTs are used to derive the efficacy parameters of the remaining comparators of interest. Outcomes from maintenance RCTs for which individual patient data are not available are usually presented in terms of durable response and remission, and sometimes durable remission. Therefore, an NMA cannot provide information on the relative efficacy of comparators for certain transition probabilities (e.g., remission to response-only, response-only to remission, response-only to active UC). Previous models have not provided a clear explanation regarding how three potential outcomes from an NMA have been used to modify/ adjust five to seven transition probabilities, derived from patient-level data from one of a few RCTs of the comparator of interest, to account for the treatment effects.

With our modeling approach, we can model the transitions between the maintenance phase health states directly using the evidence reported from RCTs and applying the comparative efficacy outcomes that can be obtained from an NMA (durable response and remission), without requiring individual patient data from RCTs to estimate all the possible transitions during the maintenance phase. At the beginning of each cycle, the number of patients in the remission and response-only health states are known. The model then uses the probability of durable response to calculate the total number of patients that remains in these two health states (remission and response-only) and the probability of remission to determine the number of patients that would be allocated to the remission health state at the end of each cycle. The difference in number of patients between those who experienced durable response and remission are allocated to the response-only health state; this allocation implies that some patients remain in the response-only health state, others improve slightly from response-only to remission, and others worsen slightly from remission to responseonly. Patients who do not experience durable response are assumed to lose their remission or response-only status and transition to the active UC health state. The limitation of this approach is that the cycle length of the maintenance phase has to be in line with the follow-up time at which the durable response and remission outcomes are reported from the RCTs.

\subsection{Limitations}

First, some RCTs included in the NMA were international, and the comparative efficacy and safety estimates from these RCTs were not specific to the Japanese population. In addition, due to a lack of available quality-of-life data for Japanese (or even Asian) patients with UC, health-state utility estimates were obtained from UK population studies. Second, the RCTs used to inform the comparative efficacy and the rates of AEs for biologics had an approximate follow-up duration of 1 year. It was assumed that the treatment effect was constant if patients remained on treatment and that transition probabilities and the incidence of AEs beyond the first year of treatment during the maintenance phase were the same as those estimated for the first year. As this analysis considered a lifetime horizon, the extrapolation of the treatment efficacy and safety after 1 year is subject to uncertainty. Third, $100 \%$ adherence to biologics was assumed (i.e., drug holidays or dose intensity were not modeled), 
which may have resulted in an overestimation of drug costs over the model time horizon; however, this impacts all biologics, potentially cancelling out any impact in favor of a specific comparator. Fourth, the impact of subsequent biologic treatment following failure of first-line biologic was not considered. After failure of the first-line biologic, patients are assumed to switch to CT, which was modeled using the placebo arm of the Japanese phase III VDZ study for patients who were anti-TNF-experienced. This assumption implies that the efficacy of CT for patients who were anti-TNF-experienced is the same after failure with all biologics, including VDZ. We decided to make this assumption and excluded subsequent lines of biologic treatment as including this feature could mask the true value of a specific first-line biologic, as benefits could result from other subsequent treatments. However, future analyses should examine the cost-effectiveness of different treatment sequences, to obtain information regarding the cost-effectiveness of specific sequences of biologics, and of individual biologics as part of a sequence of treatments and where they should be placed to maximize health economic value; the study by $\mathrm{Wu}$ et al., can provide a starting point for the future analyses [47]. Fifth, in this analysis we focused on comparing VDZ with other biologics in anti-TNF-naïve patients with moderate-to-severe UC. TOF was not included as a comparator in our analysis for the reasons stated in the "Treatment Comparators" section. If information regarding the efficacy of TOF for the treatment of anti-TNF-naïve patients with moderate-to-severe UC who have not sufficiently responded to $\mathrm{CT}$ becomes available, TOF should be included as a comparator in future analyses. Finally, IFX biosimilar was not considered a relevant comparator in our analysis for the reasons stated in the "Treatment Comparators" section. The list price of IFX biosimilar in Japan is $¥ 50,042$ for $100 \mathrm{mg}$, $62 \%$ of the price of the branded IFX ( $¥ 80,426$ for $100 \mathrm{mg}$ ). If we assume the same efficacy of the branded IFX for IFX biosimilar, IFX biosimilar would be dominant compared to ADA, GOL, and the branded IFX. VDZ would be associated with more time spent on treatment, response and remission, fewer surgeries and greater QALYs. Disease management and surgery-related costs would be also lower for patients treated with VDZ; however, inevitably, due to the lower drug acquisition cost of IFX biosimilar, its cost of treatment would be lower, as well as the total cost, resulting in an ICER above $¥ 5,000,000$ per QALY gained for VDZ versus IFX biosimilar.

\section{Conclusion}

This analysis suggests that VDZ can save costs and is more effective compared with GOL, and is cost-effective compared with ADA and branded IFX for the first-line biologic treatment of patients with moderate-to-severe active UC who have not had an adequate response with, have lost response to, or are intolerant to a CT in Japan.

Acknowledgements The authors thank Sean Smith, Senior Editor at Evidera, for his assistance in the editing, formatting, and submission of the manuscript.

Author Contributions LH led the study design, analyses, interpretation of results and writing of the manuscript, and will serve as guarantor for the overall content of the manuscript. AS participated in the study design, model programming and execution of analyses. $\mathrm{HB}, \mathrm{KF}$ and MK designed the search strategies and conducted the literature searches, data extraction and comparative efficacy analyses for the NMA. HK, KY and RI participated in the study design as well as the design of the search strategies and comparative efficacy analyses for the NMA, and the interpretation of the results. All authors were involved in the revision of this manuscript and provided final approval of the version to be published. All authors vouch for the accuracy of the content included in the full manuscript.

Data Availability Statement The authors declare that all input data to parameterize the decision analytic model are available within the article and the ESM, Online Resource 1. The model can be re-built entirely based on the detailed description of the model structure in the "Discussion" section and information provided.

\section{Compliance with Ethical Standards}

Funding This study was funded by Takeda Pharmaceutical Company Ltd. in Tokyo, Japan.

Conflict of Interest This study was funded by Takeda Pharmaceutical Company Ltd. in Tokyo, Japan. LH, AS, HB, KF and MK are all employees of Evidera, which provides consulting and other research services to pharmaceutical, medical device, and other organizations. In their salaried positions, they work with a variety of companies and are precluded from receiving payment or honoraria directly from these organizations for services rendered. Evidera received funding from Takeda Pharmaceutical Company Ltd. in Tokyo, Japan for the involvement of their employees. HK and RI are employed by Takeda Pharmaceutical Company Ltd. in Tokyo, Japan, and HK owns stocks in Takeda Pharmaceutical Company Ltd. KY was employed by Takeda Pharmaceutical Company Ltd. in Tokyo, Japan at the time the study was conducted. RI joined Takeda in January 2018; before joining Takeda, RI was an Associate Clinical Professor at the Department of Gastrointestinal Endoscopy and Internal Medicine at Saga University in Japan. RI is a key opinion leader in inflammatory bowel diseases and has authored/co-authored over 150 publications.

Overall Guarantor Luis Hernandez will serve as overall guarantor for this study and article.

Ethical Approval For this type of study, formal consent is not required, so we did not submit our study to an independent ethics committee or institutional review board. This article does not contain any studies with human participants or animals performed by any of the authors.

Informed Consent Informed consent procedures were not applicable to this study. 
Open Access This article is distributed under the terms of the Creative Commons Attribution-NonCommercial 4.0 International License (http://creativecommons.org/licenses/by-nc/4.0/), which permits any noncommercial use, distribution, and reproduction in any medium, provided you give appropriate credit to the original author(s) and the source, provide a link to the Creative Commons license, and indicate if changes were made.

\section{References}

1. Danese S, Fiocchi C. Ulcerative colitis. N Engl J Med. 2011;365(18):1713-25. https://doi.org/10.1056/NEJMra1102942.

2. Card T, Hubbard R, Logan RF. Mortality in inflammatory bowel disease: a population-based cohort study. Gastroenterology. 2003;125(6):1583-90.

3. Yamabe K, Kuwabara H, Umareddy I, Flores NM. PGI27 The burden of inflammatory bowel disease (IBD) in Japan. Value Health. 2016;19(7):A514. https://doi.org/10.1016/j. jval.2016.09.970.

4. Ng SC. Epidemiology of inflammatory bowel disease: focus on Asia. Best Pract Res Clin Gastroenterol. 2014;28(3):363-72. https ://doi.org/10.1016/j.bpg.2014.04.003.

5. Asakura K, Nishiwaki Y, Inoue N, Hibi T, Watanabe M, Takebayashi T. Prevalence of ulcerative colitis and Crohn's disease in Japan. J Gastroenterol. 2009;44(7):659-65. https://doi. org/10.1007/s00535-009-0057-3.

6. $\mathrm{Ng} \mathrm{WK}$, Wong SH, $\mathrm{Ng} \mathrm{SC}$. Changing epidemiological trends of inflammatory bowel disease in Asia. Intest Res. 2016;14(2):1119. https://doi.org/10.5217/ir.2016.14.2.111.

7. Morita N, Toki S, Hirohashi T, Minoda T, Ogawa K, Kono S, et al. Incidence and prevalence of inflammatory bowel disease in Japan: nationwide epidemiological survey during the year 1991 . J Gastroenterol. 1995;30(Suppl 8):1-4.

8. Cosnes J, Gower-Rousseau C, Seksik P, Cortot A. Epidemiology and natural history of inflammatory bowel diseases. Gastroenterology. 2011;140(6):1785-94. https://doi.org/10.1053/j.gastr o.2011.01.055.

9. Dubinsky MC. Reviewing treatments and outcomes in the evolving landscape of ulcerative colitis. Postgrad Med. 2017. https:// doi.org/10.1080/00325481.2017.1319730.

10. Ooi CJ, Fock KM, Makharia GK, Goh KL, Ling KL, Hilmi I, et al. The Asia-Pacific consensus on ulcerative colitis. J Gastroenterol Hepatol. 2010;25(3):453-68. https://doi.org/10.111 1/j.1440-1746.2010.06241.x.

11. Matsuoka K, Kobayashi T, Ueno F, Matsui T, Hirai F, Inoue N, et al. Evidence-based clinical practice guidelines for inflammatory bowel disease. J Gastroenterol. 2018;53(3):305-53. https://doi. org/10.1007/s00535-018-1439-1.

12. Health Labor and Welfare Science Research Grants Subsidy Policy Research Project for Intractable Diseases. Ulcerative colitis and Chron's disease: diagnostic criteria and treatment guidelines [in Japanese]. 2019. http://www.ibdjapan.org/pdf/doc01.pdf. Accessed 11 Jul 2019.

13. Fakuda T, Shiroiwa T. Application of economic evaluation of pharmaceuticals and medical devices in Japan. J Natl Inst Public Health. 2019;68(1):27-33.

14. Pharmaceuticals and Medical Devices Agency (PMDA). List of Approved Products. http://www.pmda.go.jp/english/review-servi ces/reviews/approved-information/drugs/0002.html. Accessed January 272019.

15. Feagan BG, Rutgeerts P, Sands BE, Hanauer S, Colombel J-F, Sandborn WJ, et al. Vedolizumab as induction and maintenance therapy for ulcerative colitis. N Engl J Med. 2013;369(8):699-710.
16. Motoya S, Watanabe K, Ogata H, Kanai T, Matsui T, Suzuki Y, et al. Vedolizumab in Japanese patients with ulcerative colitis: a phase 3, randomized, double-blind, placebo-controlled study. PLoS One. 2019;14(2):e0212989. https://doi.org/10.1371/journ al.pone.0212989.

17. Wilson MR, Azzabi Zouraq I, Chevrou-Severac H, Selby R, Kerrigan MC. Cost-effectiveness of vedolizumab compared with conventional therapy for ulcerative colitis patients in the UK. Clinicoecon Outcomes Res. 2017;9:641-52. https://doi.org/10.2147/ CEOR.S135609.

18. Wilson MR, Bergman A, Chevrou-Severac H, Selby R, Smyth M, Kerrigan MC. Cost-effectiveness of vedolizumab compared with infliximab, adalimumab, and golimumab in patients with ulcerative colitis in the United Kingdom. Eur J Health Econ. 2018;19(2):229-40. https://doi.org/10.1007/s10198-017-0879-5.

19. Trigo-Vicente C, Gimeno-Ballester V, Montoiro-Allué R, LópezDel Val A. Cost-effectiveness analysis of infliximab, adalimumab, golimumab and vedolizumab for moderate to severe ulcerative colitis in Spain. Expert Rev Pharmacoecon Outcomes Res. 2018;18(3):321-9. https://doi.org/10.1080/14737167.2018.14111 93.

20. Yokomizo L, Limketkai B, Park KT. Cost-effectiveness of adalimumab, infliximab or vedolizumab as first-line biological therapy in moderate-to-severe ulcerative colitis. BMJ Open Gastroenterol. 2016;3(1):e000093. https://doi.org/10.1136/bmjgast-2016-00009 3.

21. Hisabe T, Hirai F, Matsui T. Diagnosis of ulcerative colitis. Nippon Daicho Komonbyo Gakkai Zasshi. 2011;64(10):807-16. https ://doi.org/10.3862/jcoloproctology.64.807.

22. Clinical Study Report - Phase 3, multicenter, randomized, doubleblinded, placebo-controlled, parallel-group study to evaluate the efficacy, safety, and pharmacokinetics of intravenous MLN0002 (300 $\mathrm{mg}$ ) infusion in induction and maintenance therapy in Japanese subjects with moderate or severe ulcerative colitis (Takeda Pharmaceutical Company Limited; 1-1, Doshomachi 4-chome, Chuo-ku, Osaka-shi, Osaka). Data on file. 2016.

23. Research team on cost-effectiveness evaluation supported by Health and Labour Science Research Grants. Guideline for preparing cost-effectiveness evaluation to the Central Social Insurance Medical Council (version 2.0 approved by CSIMC on 20th February, 2019). 2019. https://c2h.niph.go.jp/tools/guideline/guide line_en.pdf. Accessed July 152019.

24. Analyses of the Japanese claims database constructed by JMDC Co. Ltd. Data on file. 2018.

25. National Institute for Health and Care Excellence (NICE). Appendix M: WinBUGS code. 2015.

26. Sandborn WJ, Feagan BG, Marano C, Zhang H, Strauss R, Johanns J, et al. Subcutaneous golimumab induces clinical response and remission in patients with moderate-to-severe ulcerative colitis. Gastroenterology. 2014;146(1):85-95. https:// doi.org/10.1053/j.gastro.2013.05.048 (quiz e14-5).

27. Rutgeerts P, Sandborn WJ, Feagan BG, Reinisch W, Olson A, Johanns J, et al. Infliximab for induction and maintenance therapy for ulcerative colitis. N Engl J Med. 2005;353(23):2462-76. https ://doi.org/10.1056/NEJMoa050516.

28. Sandborn WJ, van Assche G, Reinisch W, Colombel JF, D'Haens $\mathrm{G}$, Wolf DC, et al. Adalimumab induces and maintains clinical remission in patients with moderate-to-severe ulcerative colitis. Gastroenterology. 2012;142(2):257-65.e1-3. https://doi. org/10.1053/j.gastro.2011.10.032.

29. Thorlund K, Druyts E, Toor K, Mills EJ. Comparative efficacy of golimumab, infliximab, and adalimumab for moderately to severely active ulcerative colitis: a network meta-analysis accounting for differences in trial designs. Expert Rev Gastroenterol Hepatol. 2015;9(5):693-700. https://doi.org/10.1586/17474 124.2015.1024657. 
30. Thorlund K, Druyts E, Mills EJ, Fedorak RN, Marshall JK. Adalimumab versus infliximab for the treatment of moderate to severe ulcerative colitis in adult patients naive to anti-TNF therapy: an indirect treatment comparison meta-analysis. J Crohns Colitis. 2014;8(7):571-81. https://doi.org/10.1016/j.crohns.2014.01.010.

31. Cameron C, Ewara E, Wilson FR, Varu A, Dyrda P, Hutton B, et al. The importance of considering differences in study design in network meta-analysis: an application using anti-tumor necrosis factor drugs for ulcerative colitis. Med Decis Making. 2017;37(8):894-904. https://doi.org/10.1177/0272989X1771193 3.

32. Vickers AD, Ainsworth C, Mody R, Bergman A, Ling CS, Medjedovic J, et al. Systematic review with network metaanalysis: comparative efficacy of biologics in the treatment of moderately to severely active ulcerative colitis. PLoS One. 2016;11(10):e0165435. https://doi.org/10.1371/journ al.pone. 0165435 .

33. Reinisch W, Sandborn WJ, Hommes DW, D'Haens G, Hanauer $\mathrm{S}$, Schreiber $\mathrm{S}$, et al. Adalimumab for induction of clinical remission in moderately to severely active ulcerative colitis: results of a randomised controlled trial. Gut. 2011;60(6):780-7. https://doi. org/10.1136/gut.2010.221127.

34. Sandborn WJ, Feagan BG, Marano C, Zhang H, Strauss R, Johanns J, et al. Subcutaneous golimumab maintains clinical response in patients with moderate-to-severe ulcerative colitis. Gastroenterology. 2014;146(1):96-109.e1. https://doi. org/10.1053/j.gastro.2013.06.010.

35. Suzuki Y, Motoya S, Hanai H, Matsumoto T, Hibi T, Robinson AM, et al. Efficacy and safety of adalimumab in Japanese patients with moderately to severely active ulcerative colitis. J Gastroenterol. 2014;49(2):283-94. https://doi.org/10.1007/s0053 5-013-0922-y.

36. Kobayashi T, Suzuki Y, Motoya S, Hirai F, Ogata H, Ito H, et al. First trough level of infliximab at week 2 predicts future outcomes of induction therapy in ulcerative colitis-results from a multicenter prospective randomized controlled trial and its post hoc analysis. J Gastroenterol. 2016;51(3):241-51.

37. Jiang XL, Cui HF, Gao J, Fan H. Low-dose infliximab for induction and maintenance treatment in chinese patients with moderate to severe active ulcerative colitis. J Gastroenterol. 2015;49(7):582-8.

38. Panaccione R, Ghosh S, Middleton S, Marquez JR, Scott BB, Flint L, et al. Combination therapy with infliximab and azathioprine is superior to monotherapy with either agent in ulcerative colitis. Gastroenterology. 2014;146(2):392-400.e3. https://doi. org/10.1053/j.gastro.2013.10.052.

39. Fleurence RL, Hollenbeak CS. Rates and probabilities in economic modelling: transformation, translation and appropriate application. Pharmacoeconomics. 2007;25(1):3-6. https://doi. org/10.2165/00019053-200725010-00002.

40. Hibi T, Imai Y, Senoo A, Ohta K, Ukyo Y. Efficacy and safety of golimumab 52-week maintenance therapy in Japanese patients with moderate to severely active ulcerative colitis: a phase 3, double-blind, randomized, placebo-controlled study-(PURSUITJ study). J Gastroenterol. 2017;52:1-11.

41. Japan Intractable Diseases Information Center. Ulcerative colitis (designated intractable disease 97). http://www.nanbyou.or.jp/ entry/62. Accessed 4 Jul 2018.

42. Ministry of Health Labour and Welfare. MHLW Grant System. http://mhlw-grants.niph.go.jp/. Accessed 5 Jul 2018.

43. Kimura H, Takahashi K, Futami K, Ikeuchi H, Tatsumi K, Watanabe $\mathrm{K}$, et al. Has widespread use of biologic and immunosuppressant therapy for ulcerative colitis affected surgical trends? Results of a questionnaire survey of surgical institutions in Japan. Surg Today. 2016;46(8):930-8. https://doi.org/10.1007/s0059 5-015-1259-3.
44. Arai K, Koganei K, Kimura H, Akatani M, Kitoh F, Sugita A, et al. Incidence and outcome of complications following restorative proctocolectomy. Am J Surg. 2005;190(1):39-42. https://doi. org/10.1016/j.amjsurg.2005.05.001.

45. Selinger CP, Leong RW. Mortality from inflammatory bowel diseases. Inflamm Bowel Dis. 2012;18(8):1566-72. https://doi. org/10.1002/ibd.22871.

46. Tappenden P, Ren S, Archer R, Harvey R, James MM, Basarir H, et al. A model-based economic evaluation of biologic and nonbiologic options for the treatment of adults with moderately-toseverely active ulcerative colitis after the failure of conventional therapy. Pharmacoeconomics. 2016;34(10):1023-38. https://doi. org/10.1007/s40273-016-0409-9.

47. Wu B, Wang Z, Zhang Q. Cost-effectiveness of different strategies for the treatment of moderate-to-severe ulcerative colitis. Inflamm Bowel Dis. 2018;24(11):2291-302. https://doi.org/10.1093/ibd/ izy114.

48. Ministry of Health Labour and Welfare. Abridged Life Tables for Japan 2016. https://www.mhlw.go.jp/english/database/db-hw/lifet b16/d1/lifetb16-06.pdf. Accessed 7 Dec 2018.

49. Archer R, Tappenden P, Ren S, Martyn-St James M, Harvey $\mathrm{R}$, Basarir $\mathrm{H}$, et al. Infliximab, adalimumab and golimumab for treating moderately to severely active ulcerative colitis after the failure of conventional therapy (including a review of TA140 and TA262): clinical effectiveness systematic review and economic model. Health Technol Assess. 2016;20(39):1-326. https://doi. org/10.3310/hta20390.

50. Woehl A, Hawthorne A, McEwan P, editors. The relation between disease activity, quality of life and health utility in patients with ulcerative colitis. Gut; 2008: BMJ Publishing Group British Med Assoc House, Tavistock Square, London WC1H 9JR, England.

51. National Institute for Health and Care Excellence (NICE). Vedolizumab for the treatment of adults with moderate to severe active ulcerative colitis. Single Technology Appraisal. 2014.

52. Ministry of Health Labour and Welfare. Japan National Health Insurance drug list 2018. https://www.mhlw.go.jp/topics/2018/04/ tp20180401-01.html. Accessed 5 Sep 2018.

53. Ministry of Health Labour and Welfare. Japan National Health Insurance medical fees list 2018. https://www.mhlw.go.jp/stf/seisa kunitsuite/bunya/0000188411.html. Accessed 28 Aug 2019.

54. Barendregt JJ. The life table method of half cycle correction: getting it right. Med Decis Making. 2014;34(3):283-5. https://doi. org/10.1177/0272989X13519863.

55. Ministry of Health Labour and Welfare. Draft outline of costeffectiveness evaluation (the 409th meeting of the Central Social Insurance Medical Council) [in Japanese]. 2019. https://www. mhlw.go.jp/content/12404000/000481012.pdf. Accessed 7 Mar 2019.

56. Mamiya H. Update of drug pricing system in Japan. 2018. https ://www.mhlw.go.jp/content/11123000/000335166.pdf. Accessed 11 Jul 2019.

57. The World Bank. Life expectancy at birth, total (years). 2019. https://data.worldbank.org/indicator/sp.dyn.le00.in. Accessed 22 Jul 2019.

58. Jansen JP, Fleurence R, Devine B, Itzler R, Barrett A, Hawkins $\mathrm{N}$, et al. Interpreting indirect treatment comparisons and network meta-analysis for health-care decision making: report of the ISPOR Task Force on Indirect Treatment Comparisons Good Research Practices: part 1. Value Health. 2011;14(4):417-28. https://doi.org/10.1016/j.jval.2011.04.002.

59. Hoaglin DC, Hawkins N, Jansen JP, Scott DA, Itzler R, Cappelleri JC, et al. Conducting indirect-treatment-comparison and network-meta-analysis studies: report of the ISPOR Task Force on Indirect Treatment Comparisons Good Research Practices: part 2. Value Health. 2011;14(4):429-37. https://doi.org/10.1016/j. jval.2011.01.011. 
60. Tsai HH, Punekar YS, Morris J, Fortun P. A model of the longterm cost effectiveness of scheduled maintenance treatment with infliximab for moderate-to-severe ulcerative colitis. Aliment Pharmacol Ther. 2008;28(10):1230-9. https://doi.org/10.111 1/j.1365-2036.2008.03839.x.

61. Essat M, Tappenden P, Ren S, Bessey A, Archer R, Wong R, et al. Vedolizumab for the treatment of adults with moderate-to-severe active ulcerative colitis: an Evidence Review Group perspective of a NICE Single Technology Appraisal. Pharmacoeconomics. 2016;34(3):245-57. https://doi.org/10.1007/s40273-015-0334-3.

62. Stawowczyk E, Kawalec P. A systematic review of the cost-effectiveness of biologics for ulcerative colitis. Pharmacoeconomics. 2018;36(4):419-34. https://doi.org/10.1007/s40273-017-0601-6.

\section{Affiliations}

\section{Luis Hernandez ${ }^{1} \cdot$ Hiroyo Kuwabara $^{2} \cdot$ Anshul Shah $^{1} \cdot$ Kaoru Yamabe $^{2} \cdot$ Heather Burnett $^{3} \cdot$ Kyle Fahrbach $^{1}$. Maria Koufopoulou ${ }^{4} \cdot$ Ryuichi Iwakiri' ${ }^{2}$}

Hiroyo Kuwabara

Hiroyo.kuwabara@takeda.com

Anshul Shah

Anshul.Shah@evidera.com

Kaoru Yamabe

yamabeyk@yahoo.co.jp

Heather Burnett

Heather.Burnett@evidera.com

Kyle Fahrbach

Kyle.Fahrbach@evidera.com

Maria Koufopoulou

Maria.Koufopoulou@evidera.com
Ryuichi Iwakiri

ryuichi.iwakiri@takeda.com

1 Evidera Inc, 500 Totten Pond Road, 5th Floor, Waltham, MA 02451, USA

2 Takeda Pharmaceutical Company Ltd, 1-1, Nihonbashi-Honcho 2-chome, Chuo-ku, Tokyo 103-8668, Japan

3 Evidera Inc, 7575 Trans-Canada Hwy, Suite 404, St-Laurent, QC H4T 1V6, Canada

4 Evidera Inc, The Ark, 201 Talgarth Road, Hammersmith, London W6 8BJ, United Kingdom 